\title{
Conflitos de segunda ordem no Eixo Leste do Projeto de Integração do Rio São Francisco: análise por meio da metodologia da Cadeia Causal
}

\author{
Second-order conflicts in the East Axis of the São Francisco River \\ Integration Project: an analysis through Causal Chain Methodology
}

Tereza Helena Costa Nunes** ${ }^{1 *}$, Márcia Maria Rios Ribeiro ${ }^{\circledR}[$

\section{RESUMO}

Conflitos hídricos são decorrentes da escassez hídrica, sobretudo da ineficiência da gestão hídrica. O Projeto de Integração do Rio São Francisco com as bacias hidrográficas do Nordeste Setentrional (PISF) vem sendo desenvolvido com o objetivo de transpor água para a região semiárida do Brasil. Contudo, os problemas na execução das obras do PISF trouxeram, com a chegada da água, situações que se caracterizam como conflitos de segunda ordem. Esta pesquisa analisa as consequências da chegada acelerada das águas transpostas para o Eixo Leste do PISF, no estado da Paraíba, a fim de evitar o colapso no Reservatório Epitácio Pessoa (REP), responsável pelo abastecimento da cidade de Campina Grande e região. Usuários de água situados a montante do REP tiveram seu abastecimento prejudicado pelas obras do PISF. Metodologicamente, esta pesquisa adota a Análise da Cadeia Causal para identificar as causas do problema. As soluções apontam para a necessidade de finalização dos reparos nos reservatórios localizados a montante do REP e a proteção da população prejudicada.

Palavras-chave: governança hídrica; transposição de água; irrigação.

\begin{abstract}
Water conflicts are due to water scarcity, especially to the inefficiency of water management. The São Francisco River Basin Integration Project (PISF) has been developed aiming to transfer water to the semiarid region of Brazil. However, the problems in the execution of the PISF works brought, with the arrival of water, second-order conflicts. The research analyzes the consequences of the accelerated arrival of the waters which have been transferred to the East Axis of PISF, in the state of Paraíba, in order to avoid the collapse in the Epitácio Pessoa Reservoir (REP), responsible for supplying the city of Campina Grande and region. Water users upstream of the REP had their supply hampered by the PISF works. Methodologically, the research adopts Causal Chain Analysis to identify the causes of the problem. The solutions point to the need to complete repairs to the reservoirs located upstream of the REP and to protect the affected population.
\end{abstract}

Keywords: water governance; water transfer; irrigation.

\section{INTRODUÇÃO}

Uma situação de conflito é "um processo que começa quando um indivíduo ou grupo percebe diferenças e oposição entre si e outro indivíduo ou grupo, sobre interesses e recursos, crenças, valores ou práticas que importam para eles" (NOSR, 2007). Apesar de serem comuns à natureza humana, os conflitos, inclusive os ambientais, podem ser evitados, minimizados ou resolvidos, quando trabalhados de maneira adequada.

A água, como bem de uso comum e essencial à vida, tem motivado a ocorrência de conflitos, seja pela sua escassez, seja pela ameaça à sua qualidade, seja pela forma como ocorre a sua gestão. No caso dos conflitos envolvendo recursos hídricos, uma gestão eficiente é indispensável para evitá-los ou minimizá-los.
A gestão de recursos hídricos objetiva a exploração desses recursos de forma sustentável e equitativa, tanto por meio de ações físicas (obras hidráulicas, operação de reservatórios etc.) quanto por meio de ações não físicas (planejamento, legislações, capacitações etc.) (SAVENIJE; VAN DER ZAAG, 2002). Autores e organismos chamam a atenção para um contexto importante: mais do que motivadas pela escassez física, as crises de água são geradas pela inadequada governança do recurso (OECD, 2011; PRESSE, 2015; PAHL-WOSTL, 2017).

Nessa discussão, Ohlsson (1999; 2000) faz uma importante distinção entre o que conceitua como recurso de primeira ordem e recurso de segunda ordem. Recurso de primeira ordem é qualquer recurso natural que pode ser escasso ou abundante, espacialmente, temporalmente e com relação à qualidade. Recurso de

'Universidade Federal de Campina Grande - Campina Grande (PB), Brasil.

*Autora correspondente: eng.terezanunes@gmail.com

Conflitos de interesse: os autores declaram não haver conflito de interesses.

Financiamento: Conselho Nacional de Desenvolvimento Científico e Tecnológico (CNPq), por meio do Projeto Governança de água: análise e avaliação em contexto de múltiplas escalas e dupla dominialidade.

Recebido: 21/11/2019 - Aceito: 02/07/2O2O - Reg. ABES: 20190367 
segunda ordem se refere a ferramentas sociais apropriadas (que podem ser escassas ou não) para lidar com as consequências da escassez de primeira ordem. Isto é, recurso de segunda ordem é o tipo de recurso que se faz necessário para, efetivamente, lidar com a escassez do recurso de primeira ordem. Interessa, portanto, verificar se há recursos sociais adequados para vencer a escassez de primeira ordem. Na continuidade dessa discussão, duas categorias de conflitos são definidas (OHLSSON; TURTON, 1999; OHLSSON, 2000): conflitos de primeira ordem, derivados da escassez do recurso natural; e conflitos de segunda ordem, gerados pela forma como os recursos sociais (por exemplo, as medidas a serem tomadas) são utilizados (ou não) para superar a escassez de primeira ordem.

Além de conflitos pontuais entre usuários de água, o atual processo de mudança (positiva e necessária) da velha governança da água, em que as ações e as decisões são pensadas por um pequeno grupo detentor de poder, para a nova governança, na qual todas as ações, os planejamentos e as legislações são pensados e opinados de maneira descentralizada e participativa (SCHULZ et al., 2017), acaba também por gerar conflitos, visto que tais mudanças envolvem vários setores.

Entre os estudos que abordam conflitos hídricos no Brasil, Fleury e Almeida (2013) analisam o conflito decorrente da construção da usina hidrelétrica de Belo Monte, no estado do Pará. Silva et al. (2015) desenvolvem um estudo para análise de conflitos por água nos estados beneficiados com o projeto de integração do rio São Francisco. Oliveira, Zanquim Júnior e Espíndola (2016) realizam um estudo sobre a Política Nacional de Recursos Hídricos (PNRH), com relação à competência dos Comitês de Bacia para arbitrar conflitos em recursos hídricos, por meio do uso de ferramentas alternativas. Em Amorim, Ribeiro e Braga (2016), investigam-se os conflitos em bacias compartilhadas por diferentes unidades federativas com foco para a Bacia do rio PiranhasAçu, compartilhada entre a Paraíba e o Rio Grande do Norte. Mecanismos de resolução de conflitos na Bacia do rio Piranhas-Açu e na Bacia do rio Tejo (Portugal e Espanha) são discutidos em Ribeiro et al. (2019). Entre tais mecanismos, os autores citam as regras legais, a consulta e participação públicas, os mecanismos de preços e as autoridades estabelecidas em nível de bacias. Um exemplo com o rio Eufrates, na Ásia Ocidental, é detalhado em Mianabadi et al. (2014). Os autores desenvolvem uma nova regra para a resolução de conflitos sobre compartilhamento de rios. Um caso chinês (na província de Heilongjiang, nordeste do país) é explorado em Zou et al. (2018), que averiguam conflitos pelo uso da água entre terras de zona úmida e terras de produção agrícola na planície de Sanjiang.

A região semiárida do Brasil é cenário de vários conflitos pelo uso múltiplo dos recursos hídricos, em parte por esses serem escassos, uma vez que tal região tem entre suas características a ausência de rios perenes e as chuvas irregulares espacial e temporalmente. Entretanto, a má gestão dos recursos hídricos tem sido apontada como a principal responsável pelo agravamento das situações de escassez (RÊGO et al., 2014).

Com a promessa de levar "Água a quem tem sede" (BRASIL, 2019a) e resolver os problemas de escassez hídrica no semiárido brasileiro, o Projeto de Integração do Rio São Francisco com as bacias hidrográficas do Nordeste Setentrional (PISF), popularmente conhecido como transposição do rio São Francisco, teve sua construção iniciada na última década. A governança de água, entretanto, no âmbito da transposição das águas da Bacia do rio São Francisco, tem sido elemento de reflexão. Freitas (2015) estudou as mudanças nas modalidades de governança da água no contexto da neoliberalização da natureza, tendo como estudo de caso a Bacia do rio São Francisco. Nesse estudo, o autor afirma que, apesar das mudanças propostas para a governança de água no Brasil após 1997 (pós-Lei das Águas), as formas de gestão ainda seguem padrões antiquados de dominialidade elitista. Rodorff et al. (2015) estudaram a governança da Bacia Hidrográfica do rio São Francisco com o objetivo de "colaborar para a discussão acerca das possibilidades e dos limites de gestão da bacia segundo a perspectiva da governança territorial", tendo como foco a análise social empírica do reservatório Itaparica. Os autores constataram, entre outras questões, a pouca representatividade do comitê de bacia junto à população.

Apesar de parte da obra do PISF ainda estar em andamento (eixo Norte) (BRASIL, 2019b), as águas da transposição chegaram ao semiárido paraibano, apressadamente, pelo Eixo Leste do projeto em março de 2017, como única solução para evitar o colapso do abastecimento da cidade de Campina Grande e região. Essa região vivenciou uma severa estiagem no período 2012-2017 e o Reservatório Epitácio Pessoa (REP), responsável pelo seu abastecimento, alcançara 3\% do seu volume máximo em abril de 2017 (RÊGO et al., 2017). Visando solucionar os conflitos pelo uso da água (ressaltados pela competição entre abastecimento público e irrigação), a chegada da transposição, entretanto, trouxe problemas para usuários localizados a montante do REP. Este artigo objetivou analisar essa situação envolvendo o Eixo Leste da transposição do rio São Francisco na Paraíba. Para isso, utilizou-se da metodologia da Análise da Cadeia Causal - ACC (GIWA, 2002).

\section{ANÁLISE DA CADEIA CAUSAL}

O modelo conceitual utilizado nesta pesquisa foi apresentado, inicialmente, para o projeto Global International Waters Assessment (GIWA), do Programa das Nações Unidas para o Meio Ambiente (PNUMA), e propõe o desenvolvimento de uma estrutura estratégica e conceitual com o objetivo de encontrar formas de mitigar problemas e impactos envolvendo águas internacionais (GIWA, 2002). Belausteguigoitia (2004) considera que a ACC indica rumos de causa-efeito em impactos socioeconômicos e ambientais, possibilitando ao analista encontrar a raiz do problema.

A metodologia vem sendo utilizada para estudos de problemas e conflitos em diversas áreas. He, Chen e Yang (2014) realizam uma análise causal no monitoramento multivariado de processos estatísticos, utilizando os conceitos de conjuntos difusos. Kampen (2014) aplica a metodologia para verificar o desdobramento do padrão de esquizofrenia em pacientes utilizando linguagem de grafos direcionados. Lee e Park (2017) analisam as relações socioeconômicas entre saúde e nutrição de crianças na Coreia. Lemay Jr. e Ryan (2018) averiguam, por meio de análise de cadeia causal, um novo modelo de regulação interpessoal em relacionamentos com base na segurança dos parceiros. Schram et al. (2018) desenvolvem uma estrutura conceitual para investigar os impactos do comércio internacional e do investimento em acordos sobre doenças não transmissíveis, analisando fatores de risco. Liao et al. (2018) desenvolvem um modelo de influência que relaciona o erro humano ao ambiente de trabalho. Kneale et al. (2018) descrevem modelos lógicos para delinear, graficamente, como intervenções levam a mudanças em resultados por meio da representação de cadeia causal de eventos, visando auxiliar revisores sistemáticos na produção de resultados úteis a tomadores de decisão. White (2018) apresenta uma abordagem baseada em teoria para revisões sistemáticas, por meio de questões surgidas na ACC de métodos mistos. 
Um exemplo para o setor hídrico é encontrado em Liang et al. (2011), que averiguam os problemas de enchentes no lago Taihu, no leste da China. Em Miao et al. (2015), há análise para casos representativos de poluição industrial da água, também, na China. Os autores confirmam que a situação ocorre, principalmente, em função de problemas institucionais e sugerem formas de governança ambiental para prevenir e mitigar a poluição ambiental. Um caso brasileiro é explorado por Silva, Ribeiro e Miranda (2017), que utilizam cadeia causal na análise institucional da gestão de recursos hídricos do REP (corpo hídrico no Eixo Leste do PISF, foco desta pesquisa). Os autores concluem que as falhas e as ameaças de colapso no reservatório se deram pela falta de articulação e integração das entidades gestoras. A degradação da Bacia Hidrográfica do rio Iguaçu, no Paraná, é avaliada em Blanc, Ferronato e Miranda (2017). Os autores consideram temas prioritários, como poluição hídrica; degradação do solo e assoreamento; alteração da disponibilidade hídrica; alteração da biodiversidade; e fragilidade econômica, política e institucional. Entre as causas raízes aos problemas, estão a ausência de investimentos em setores estratégicos (entre eles, o saneamento) e a inexistência de integração de políticas públicas. Outro exemplo brasileiro está em Soares (2015). Na pesquisa, a cadeia causal é usada para analisar problemas ambientais nas nascentes (periurbana e rurais) da Bacia Hidrográfica do rio Gramame, na Paraíba (manancial abastecedor de João Pessoa). Conflitos pelo uso da água, nível socioeconômico e fontes de poluição foram os aspectos abordados. A autora conclui que os conflitos possuem tendência de agravamento.

\section{CASO DE ESTUDO}

O PISF, mais conhecido como Transposição do rio São Francisco, tem sua origem ainda no Brasil Colônia, mas suas obras foram iniciadas apenas em 2007. Tal projeto se configura como a maior obra em recursos hídricos do Brasil (BRASIL, 2004; 2019b).

O PISF propõe beneficiar cerca de 12 milhões de habitantes, e é composto de dois sistemas independentes: o Eixo Norte e o Eixo Leste. O primeiro transpõe a água para os rios Brígida (Pernambuco), Salgado (Ceará), do Peixe e Piranhas-Açu (Paraíba e Rio Grande do Norte) e Apodi (Rio Grande do Norte), permitindo o abastecimento dos açudes Chapéu (Pernambuco), Entremontes (Pernambuco), Castanhão (Ceará), Engenheiro Ávidos (Paraíba), Pau dos Ferros (Rio Grande do Norte), Santa Cruz (Rio Grande do Norte) e Armando Ribeiro Gonçalves (Rio Grande do Norte). E o segundo transpõe a água para o açude Poço da Cruz (Pernambuco) e o rio Paraíba, o qual aflui para os açudes São José, Poções, Camalaú e Epitácio Pessoa, na Paraíba (BRASIL, 2004). A localização do projeto pode ser visualizada na Figura 1.

Com previsão de conclusão para o ano de 2012, o PISF ainda é um projeto em andamento. As obras do Eixo Leste, área de estudo deste artigo, precisaram ser "adiantadas"/concluídas às pressas em decorrência da última crise vivenciada pela região semiárida, iniciada em 2012, e do risco iminente de colapso do REP, responsável por abastecer uma população de aproximadamente 1 milhão de habitantes (RÊGO et al., 2017).

Para o caso em análise, verifica-se que desde a primeira crise hídrica no REP (RÊGO; GALVÃO; ALBUQUERQUE, 2012), o que poderia ser interpretado como uma escassez de recursos naturais (escassez de primeira ordem) - uma competição pelo uso da água entre o abastecimento público e a irrigação foi, de fato, uma escassez de segunda ordem. Já naquele período (1998-2003), estiveram ausentes, ou foram introduzidas tardiamente (RÊGO et al., 2013), as medidas necessárias para evitar o conflito de primeira ordem, transformando-o em um conflito de segunda ordem.

O período 2004-2011 se configurou, na região semiárida brasileira, como de normalidade hidrológica com reservatórios, tendo seus armazenamentos extrapolados, caso que ocorre, também, com o REP (Figura 2). Com a chegada do primeiro ano do segundo ciclo de estiagem (2012), recursos de segunda ordem não introduzidos nem na primeira crise hídrica, nem no período de normalidade, nem nos primeiros anos da segunda crise, levaram o REP a alcançar o valor de 3\% de sua capacidade total em 2017. Estava caracterizado, mais uma vez, o conflito de segunda ordem (que permanecera latente durante os anos de normalidade hidrológica).

No último ano de afluências muito abaixo da média (2017), o REP, que abastece Campina Grande e mais 17 municípios na Paraíba, e que já vinha operando em seu volume morto desde meados de 2016, alcançou o menor percentual de volume armazenado de sua história (AESA, 2020). Tal fato ocorreu em abril de 2017 (Figura 2). O desabastecimento total da população foi evitado em função da chegada das águas transpostas do rio São Francisco ao rio Paraíba em março e ao reservatório, em abril.

\section{As consequências da chegada do Projeto de Integração do Rio São Francisco com as bacias hidrográficas do Nordeste Setentrional: Eixo Leste (Paraíba)}

Para que a vazão da transposição chegasse ao REP, evitando o colapso no abastecimento proveniente dele, intervenções foram feitas a montante daquele

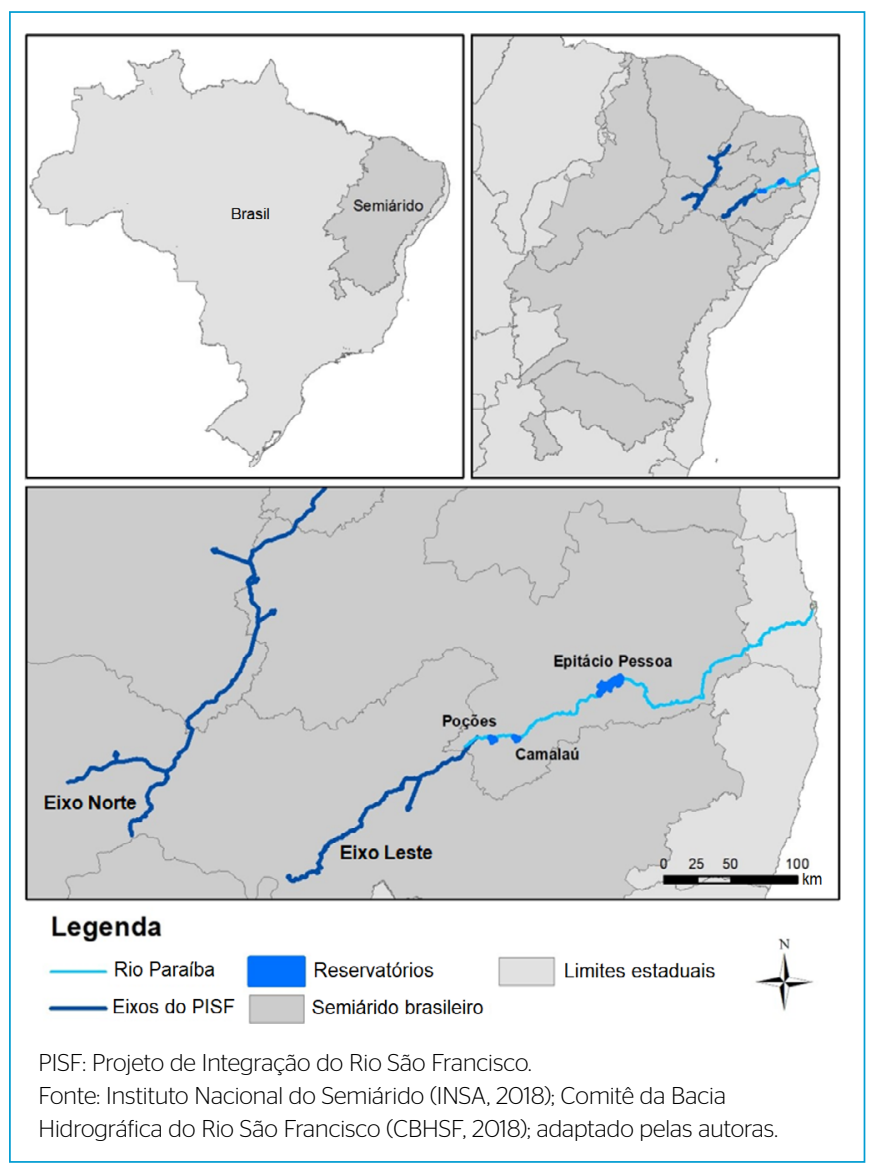

Figura 1- Localização do Projeto de Integração do Rio São Francisco: eixos Norte e Leste. 
reservatório. Entre essas, a execução de um canal escavado por meio dos vertedouros das barragens Poções e Camalaú (Figura 1), o que permitiu que a água vertesse mais rapidamente.

O Reservatório Poções localiza-se no município de Monteiro, Paraíba. O reservatório tem capacidade máxima de armazenamento de $29,86 \mathrm{hm}^{3}$ e vazão de regularização de $0,20 \mathrm{~m}^{3} / \mathrm{s}$. Poções é utilizado para abastecimento humano (urbano e rural) do município de Monteiro (30.852 habitantes - IBGE, 2010) (57\%), para dessedentação animal (30\%) e para irrigação (13\%) (ANA, 2017).

O Reservatório Camalaú (a jusante de Poções) localiza-se, também, no município de Monteiro, Paraíba. O reservatório tem capacidade máxima de armazenamento de $46,44 \mathrm{hm}^{3}$ e vazão de regularização de $0,24 \mathrm{~m}^{3} / \mathrm{s}$. É usado para abastecimento humano (urbano e rural) dos municípios de Camalaú (5.749 habitantes - IBGE, 2010) e São João do Tigre (4.396 habitantes - IBGE, 2010) (67\%), para dessedentação animal (23\%) e para irrigação (11\%) (ANA, 2017).

Apesar das intervenções nas barragens descritas anteriormente terem sido justificadas, à época, pelo Departamento Nacional de Obras Contra as Secas (DNOCS), como sendo de caráter emergencial, pela urgência da chegada da água ao REP (Figura 1), elas afetaram a população dependente dos reservatórios, uma vez que o canal impediu que eles cumprissem sua função de armazenar água. Dessa forma, para resolver conflitos de segunda ordem no REP, por meio do PISF, outros conflitos (de segunda ordem) são gerados.

Em 16 de março de 2018, em reunião, com a presença de representantes do Ministério Público Federal na Paraíba (MPF-PB), do Ministério da Integração Nacional, da Agência Nacional de Águas (ANA), da Agência Executiva de Gestão das Águas da Paraíba (AESA), do DNOCS, da Companhia de Desenvolvimento dos Vales do São Francisco e do Parnaíba (CODEVASF), da Secretaria de Estado dos Recursos Hídricos, do Meio Ambiente e da Ciência e Tecnologia e do Comitê de Bacia Hidrográfica do rio São Francisco, decidiu-se pelo desligamento provisório do sistema do Eixo Leste do PISF (BRASIL, 2018). Tal fato ocorreu pela necessidade de execução de obras para reparar os reservatórios Poções e Camalaú, considerando-se que o rompimento das barragens durante as chuvas afetaria todo o PISF-Eixo Leste. O volume de água armazenado no REP nesse período (cerca de 15\% de sua capacidade de armazenamento, conforme AESA, 2020), resultado das chuvas ocorridas na região em 2018, apresentava uma "segurança hídrica" para os próximos meses.

As obras nos reservatórios Poções e Camalaú foram previstas, inicialmente, para durarem quatro meses (até o início de agosto de 2018). O MPF-PB e o Ministério Público do Estado da Paraíba (MP-PB), juntamente com o DNOCS e a AESA, realizaram vistorias às obras de reparo dos reservatórios (MPF-PB, 2018a). Em uma dessas visitas foram identificadas irregularidades, inclusive com relação à segurança dos trabalhadores, o que levou a um embargo da obra até que as irregularidades fossem sanadas. Tais fatos atrasaram os reparos. O MPF-PB e o MP-PB estipularam como novo prazo para conclusão das obras a data de 30 de setembro de 2018 (G1-PB, 2018). Entretanto, o novo prazo não foi cumprido.

Estando as obras nos reservatórios já bem avançadas, em setembro de 2018 a vazão da transposição voltou a ser liberada para o Eixo Leste (BARBOSA, 2018). Todavia, de acordo com o MPF, em fiscalização realizada em 20 de novembro de 2018, foi constatado que a vazão que chegava ao Reservatório Poções não era suficiente para atingir o Reservatório Camalaú e, consequentemente, não estaria atingindo o REP (MPF-PB, 2018b).

Em 11 de janeiro de 2019, o DNOCS afirmou que os serviços no vertedouro, as comportas e as grades da Barragem de Camalaú estavam concluídos, estando ainda em andamento a execução da torre da tomada d'água suplementar

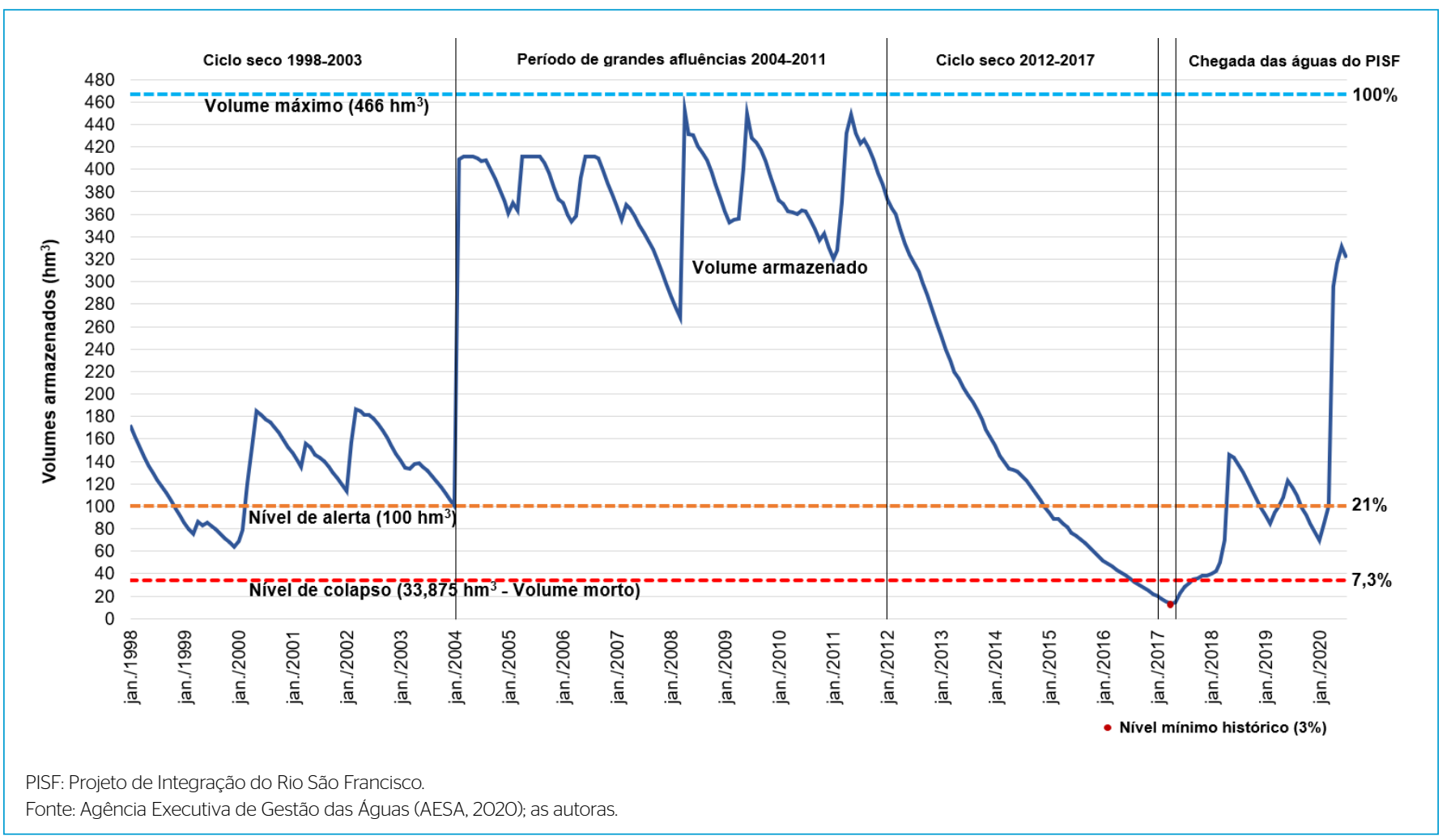

Figura 2 - Volumes armazenados no Reservatório Epitácio Pessoa entre 1998 e 2020. 
(70\%) e o reaterro da galeria. A previsão de conclusão seria março de 2019. Na Barragem de Poções estavam concluídos o assentamento da tubulação e a caixa de entrada da Torre de Tomada d'água Suplementar (TMDS), estando em execução o alargamento do vertedouro e a casa de comando (DNOCS, 2019b).

Até o fechamento deste artigo (novembro de 2019), as obras nas barragens, apesar de bem avançadas, ainda não estavam concluídas. De acordo com o DNOCS, a previsão para conclusão das obras na Barragem de Poções é para dezembro de 2019, quando se encerra o contrato com a empresa responsável pela obra. Já no caso da Barragem de Camalaú, estava em processo uma nova licitação para contratar empresa para concluir os serviços.

\section{Resoluções Agência Nacional de Águas e Agência Executiva de Gestão das Águas da Paraíba para o Sistema Hídrico rio Paraíba: Boqueirão}

Após as chegadas das águas do PISF à Paraíba, ANA e AESA, em 17 de julho de 2017, lançaram a resolução conjunta no 1.292 (ANA; AESA, 2017), estabelecendo condições de uso para os recursos hídricos superficiais e subterrâneos para o Sistema Hídrico rio Paraíba - Boqueirão durante o período de pré-operação do PISF. Tal sistema é formado pelo rio Paraíba, do deságue do Eixo Leste do PISF em Monteiro, Paraíba, até o REP (conhecido por Boqueirão).

A partir dessa resolução, a Companhia de Água e Esgotos da Paraíba (CAGEPA), autorizada, anteriormente, a captar do REP o valor de $1.100 \mathrm{~L} / \mathrm{s}$ (Ofício Conjunto ${ }^{\circ}$ 1/2017/AR-JL-ANA/AESA, de 20 de abril de 2017), ficou permitida a captar uma vazão média mensal de até $1.300 \mathrm{~L} / \mathrm{s}$, para atendimento aos sistemas Cariri e Campina Grande.

A captação de água do Sistema rio Paraíba - Boqueirão, incluindo os reservatórios São José II, Poções, Camalaú e Epitácio Pessoa, passou a ser realizada apenas para suprimento das demandas consumo humano, dessedentação animal e agricultura de subsistência (com limitações de área, horas, cultura cultivada, entre outras).

Tal resolução vigorou até 26 de março de 2018, quando o PISF deveria encerrar o seu período de pré-operação (após um ano do início do funcionamento no sistema) e passar à primeira fase de operação. Entretanto, esse período foi prorrogado até 31 de dezembro de 2018 (Outorga no 301, de 15 de março de 2018). Essa resolução foi revogada com a publicação da resolução conjunta ANA/AESA-PB no 87, de 5 de novembro de 2018 (ANA; AESA, 2018).

A nova resolução manteve a maioria dos critérios de uso da água da resolução anterior, com alguns acréscimos. Foram adicionadas novas limitações relacionadas à área irrigada, ao volume captado e à emissão de autorização para captação. Esse aspecto merece destaque, já que indica um caminho para legalização dos irrigantes do sistema, uma vez que, até aquele momento, esses usuários operavam na ilegalidade, isto é, sem o termo de outorga.

\section{Planos de segurança de barragem}

Em 7 de fevereiro de 2019, o MPF pediu à justiça o bloqueio de 1 milhão de reais das contas do DNOCS e do estado da Paraíba pelo descumprimento de acordo judicial que determinava a elaboração de Planos de Segurança de Barragem para os reservatórios Poções e Camalaú. O acordo foi firmado em 08 de agosto de 2017, em audiência de conciliação na Justiça Federal, em Monteiro. Com intuito de vistoriar a situação das obras de recuperação e modernização das barragens e o cumprimento dos requisitos instituídos na Política Nacional de Segurança de Barragens (PNSB), um analista pericial do MPF realizou visitas técnicas em
31 de janeiro de 2019 e $1^{\circ}$ de fevereiro de 2019, constatando o descumprimento do acordo (MPF-PB, 2019a).

De acordo com a Informação Técnica MPF/PRPB nº 04/2019, é "fundamental a existência do Plano de Segurança de Barragem e do Plano de Ação Emergencial dos respectivos reservatórios” (MPF-PB, 2019e). Ainda, segundo a Informação Técnica, apesar de a Barragem de Camalaú apresentar "Categoria de Risco" inferior à de Poções, o risco dos dois reservatórios é interligado, uma vez que os reservatórios são próximos (Figura 1), têm capacidades de armazenamento semelhantes e estão conectados pelo rio Paraíba. O rompimento de ambas ou de uma dessas barragens implicaria em danos à comunidade e ao meio ambiente.

Em 26 de março de 2019, em audiência de conciliação, o MPF suspendeu os bloqueios e designou audiência de conciliação a partir de 24 de julho de 2019, ficando intimados, o Estado da Paraíba e o DNOCS, para elaborar Relatório de Inspeção atualizado acerca da situação da segurança das barragens de Poções e Camalaú, até a realização do ato conciliatório, sob pena de multa de $\mathrm{R} \$ 10.000$ para cada, caso comparecessem ao futuro ato sem a realização das inspeções. De acordo com a AESA, responsável pelo plano da Barragem de Camalaú, ele já está sendo elaborado por empresa contratada e deve ficar pronto até o final de 2019 (MPF-PB, 2019b). Com relação ao plano da Barragem de Poções, o DNOCS informou que já houve licitação e está em processo de contratação de empresa para elaboração.

\section{População atingida no conflito de segunda ordem}

Em termos de população a usufruir das águas transpostas do rio São Francisco no seu Eixo Leste, dois grupos populacionais se destacam: a população dos municípios abastecidos pelos reservatórios Poções e Camalaú e a população de Campina Grande e região. Observa-se que, para garantir a chegada das águas transpostas até o REP, uma população a montante dele foi afetada (caracterizando-se um conflito de segunda ordem). A cidade de Monteiro, porta de entrada para as águas do PISF-Eixo Leste na Paraíba, em abril de 2017, pouco mais de um mês após a chegada das águas, ainda sofria com o racionamento de água, sem que houvesse previsão de encerramento dele. De acordo com a CAGEPA, a razão seria os volumes baixos dos reservatórios. Sabe-se que, com a interferência nas barragens, o volume deles estava afetado, o que provavelmente fez com que o racionamento perdurasse, mesmo com as águas transpostas (G1-PB, 2017).

Segundo informações obtidas no site da CAGEPA, em dezembro de 2018, responsável pelo abastecimento dos municípios Monteiro e Camalaú, envolvidos no conflito, o abastecimento deles encontrava-se normalizado.

Ainda no município de Monteiro, 61 famílias, que viviam da produção agrícola familiar, foram retiradas de suas terras para a construção do PISF. Elas foram realocadas na Vila Produtiva Rural Lafayette, com a promessa de uma nova fonte de produção e renda por meio da irrigação com as águas da transposição. Contudo, até a conclusão do presente artigo (novembro de 2019), mais de dois anos e sete meses após a chegada das águas, a Vila Produtiva Lafayette continuava desabastecida. A população da vila, que não tem como produzir, tem sobrevivido com benefício assistencial do Governo Federal, uma situação frustrante para pessoas que foram removidas de suas comunidades, onde havia tanto valor emocional quanto independência produtiva, para permitir a construção do PISF. Muitas famílias ainda não receberam a indenização decorrente da desapropriação (MPF-PB, 2019c). 
Em agosto de 2019, o MPF-PB emitiu a recomendação nº 5/2019 à Secretaria Nacional de Segurança Hídrica do Ministério do Desenvolvimento Regional para que ela adotasse medidas efetivas para implementar o sistema de abastecimento de água para irrigação destinado à Vila Produtiva Rural Lafayette, no prazo de 90 dias (MPF-PB, 2019d).

Entre 2018 e 2019, o bombeamento da transposição foi suspenso e religado diversas vezes. Em abril de 2019, a vazão foi suspensa mais uma vez, pela necessidade de sanar problemas de vazamento de água na Barragem de Cacimba Nova, em Custódia, Pernambuco (DNOCS, 2019a). Com o problema controlado, a água foi novamente liberada a caminho da Paraíba em novembro de 2019. Até o fechamento deste artigo (20 de novembro de 2019), as águas ainda não haviam chegado a Monteiro, o que se justifica por, no PISF, existirem reservatórios a montante de Monteiro que precisam chegar a certo nível para que a água siga o curso. Acredita-se que as águas chegarão à Paraíba entre o fim de novembro e início de dezembro.

\section{METODOLOGIA}

A situação foi estudada por meio da esquematização da cadeia causal (GIWA, 2002). Baseando-se em Silva, Ribeiro e Miranda (2017), consideraram-se as causas político-gerenciais (CPGs), as causas técnicas (CTs) e as causas socioeconômico-culturais (CSCs), as quais estão intimamente relacionadas:

- CPGs: são as que surgem por meio de instabilidade ou desarranjo, especialmente por incapacidade política e gerencial. Elas podem ser minimizadas por novos arranjos institucionais e/ou regulamentações, ocasionando melhorias na operação do sistema;

- CTs: podem ser um resultado da falta de ações técnicas que são geradas por ineficiência das ações políticas e/ou gerenciais, ou de condições econômicas e culturais;

- CSCs: são aquelas constituídas e consolidadas por meio de razões de ordem econômica ou cultural.
Após a identificação das causas político-gerenciais, técnicas e socioeconômico-culturais, analisou-se o aspecto da tendência. Esse aspecto possibilita um direcionamento ao planejamento de ações que permitam chegar a soluções ou mitigação dos problemas. Foram atribuídas tendências de agravamento $(\boldsymbol{\nabla})$, quando o problema tende a piorar; melhoria $(\boldsymbol{\Lambda})$, quando a situação aponta para uma possível alteração positiva; ou permanência (๘), quando a análise indica uma permanência da situação, com base no atual estado do conflito.

Atrelada à tendência, foi realizada uma classificação de estabilidade ou instabilidade dela. Nessa classificação, a tendência é apontada como estável ( $\bullet$ ) para a situação em que há impossibilidade de alterações em um futuro próximo; ou instável ( $\odot$ ), em uma situação em que existe a possibilidade de alteração dessa tendência em um futuro próximo, caso ocorram mudanças.

Foram atribuídos níveis de prioridade para ações que permitam a busca por soluções para os problemas gerados em torno das causas, quais sejam: mais importante (1); intermediário (2); e menos importante (3). A classificação de prioridade está atrelada à urgência em resolver os problemas em torno de determinada causa.

\section{RESULTADOS E DISCUSSÃO}

Na construção da cadeia causal, foram incluídos acontecimentos anteriores ao período de março de 2017 (chegada das águas do PISF ao rio Paraíba), uma vez que esse contexto gerou a urgência da transposição das águas do rio São Francisco. As causas analisadas são apresentadas a seguir. Elas estão resumidas no Quadro 1 e a cadeia causal está ilustrada na Figura 3.

\section{Causas político-gerenciais}

Uma das principais causas, que gerou a maioria das demais, foi o "atraso na execução das obras do PISF”. A previsão inicial para conclusão do PISF era o ano de 2012, início do ciclo de anos com chuvas abaixo da média. Caso não

Quadro 1 - Resumo das causas da cadeia causal.

\begin{tabular}{|c|c|c|c|c|}
\hline \multicolumn{2}{|l|}{ Causas } & Tendência & Estabilidade & Prioridade \\
\hline \multirow{3}{*}{ Político-gerenciais } & $\begin{array}{c}\text { Atraso na execução das obras do Projeto de Integração do rio } \\
\text { São Francisco }\end{array}$ & Permanência & Instável & Mais importante \\
\hline & Decisões emergenciais por parte dos órgãos gestores & Melhoria & Instável & Intermediário \\
\hline & Posicionamentos tardios por parte do órgão gestor do REP & Agravamento & Instável & Mais importante \\
\hline \multirow{4}{*}{ Técnicas } & "Aceleramento" das obras & Melhoria & Instável & Mais importante \\
\hline & Construção do canal escavado nos vertedores dos reservatórios & Melhoria & Estável & Mais importante \\
\hline & $\begin{array}{c}\text { Continuação do racionamento nos municípios abastecidos pelos } \\
\text { reservatórios afetados }\end{array}$ & Melhoria & Instável & Mais importante \\
\hline & Ausência de vazão para produção agrícola familiar & Permanência & Instável & Mais importante \\
\hline \multirow{5}{*}{ Socioeconômico-culturais } & Indústria da seca & Melhoria & Instável & Intermediário \\
\hline & $\begin{array}{l}\text { Priorização do abastecimento de Campina Grande e região em } \\
\text { detrimento dos municípios abastecidos por Poções e Camalaú }\end{array}$ & Permanência & Estável & Menos importante \\
\hline & Prejuízos decorrentes do racionamento & Permanência & Instável & Mais importante \\
\hline & $\begin{array}{l}\text { Representatividade de Campina Grande enquanto polo } \\
\text { econômico e industrial }\end{array}$ & Permanência & Estável & Menos importante \\
\hline & $\begin{array}{c}\text { Adiamento do crescimento econômico dos produtores familiares } \\
\text { afetados pela intervenção nos reservatórios }\end{array}$ & Permanência & Instável & Mais importante \\
\hline
\end{tabular}

REP: Reservatório Epitácio Pessoa.

Fonte: elaborado pelas autoras. 
ocorressem atrasos, à medida que o volume dos reservatórios era reduzido com a falta de chuvas, o PISF entraria em funcionamento, evitando todos os problemas e conflitos decorrentes do fenômeno climático (nitidamente agravado pela falta de uma gestão eficiente). Essa causa é apontada como em estado de permanência, já que as obras do PISF continuam inacabadas até o momento (novembro de 2019). A causa foi considerada instável, visto que, apesar de a obra estar fora do prazo (2012), sua execução continua em andamento. Para essa causa, a prioridade atribuída foi 1 , uma vez que ela já deveria ter sido concluída.

A segunda CPG identificada foram as "decisões emergenciais por parte dos órgãos gestores" (ANA, AESA e DNOCS). Apesar da inegável urgência de evitar o colapso no REP, as escolhas por parte dos órgãos gestores desencadearam a situação aqui analisada. Tal causa apresenta uma tendência de melhoria em razão da possível saída do ciclo de anos secos. A tendência foi considerada instável, visto que esse cenário pode se alterar com a chegada de um novo ciclo seco, com a continuação do atual, com os problemas de estiagens na Bacia do rio São Francisco e com o não aprendizado com a crise iniciada em 2012. Assim, atribuiu-se a prioridade 2.

A terceira CPG identificada foram os "Posicionamentos tardios por parte do órgão gestor do reservatório Epitácio Pessoa”. Os atrasos nas tomadas de decisão por parte da ANA, responsável pela gestão das águas do REP, tem grande impacto nos conflitos pelo uso da água. Houve ausência de decisões eficientes, rápidas e acertadas. Nesse sentido, chama a atenção o tratamento dado pela Agência ao usuário da irrigação das águas do REP, retardando a suspensão dessa atividade. A irrigação, mesmo sem outorga, continuou a ocorrer, com o consentimento da ANA, até o terceiro ano do ciclo seco (RÊGO et al., 2014). Uma atitude distinta dessa teria gerado armazenamentos no REP mais favoráveis no ano de 2017, o que poderia evitar as intervenções emergenciais nas barragens de Poções e Camalaú. Essa causa pode ter uma tendência de agravamento, se as águas do PISF não forem bem gerenciadas. A tendência é considerada instável, visto que uma ineficiência dessa gestão pode ser resolvida com investimentos e melhorias na governança. Para essa causa, foi atribuída a prioridade 1 .

\section{Causas técnicas}

As CTs foram relacionadas com as CPGs. A primeira delas é o “aceleramento' das obras", tendo em vista que as obras estavam (e estão) atrasadas. Tal causa tem conexão com a CPG "Atraso na execução das obras do PISF", já que sem os atrasos essa causa não existiria. A causa apresenta tendência de melhoria, uma vez que as obras estão em andamento. As chuvas de 2018 trouxeram certo conforto com a recarga do REP (aproximadamente 36\% da capacidade de armazenamento em maio de 2018), apontando o encerramento do ciclo de anos secos. Em 2019, as recargas foram menos expressivas (chegando a maio com aproximadamente $23 \%$ de sua capacidade). Um novo ciclo de anos chuvosos pode resultar em um novo "relaxamento" na execução das obras, voltando estas ao ritmo anterior. Por essa razão, a tendência foi considerada instável, sendo atribuída prioridade 1.

A segunda CT, "Construção do canal escavado nos vertedores dos reservatórios", na prática, é a responsável pela possibilidade de indução de conflitos de segunda ordem. Tem ligação com as três CPGs, uma vez que ela é a causa central do conflito. Tem tendência de melhoramento, visto que as obras para reparo dessa intervenção emergencial estão sendo realizadas, apesar de também apresentarem atrasos. A causa foi considerada estável. Em razão da urgência na conclusão das obras de reparo nos dois reservatórios, foi atribuída para essa causa a prioridade 1 .

A intervenção nos reservatórios resultou na "Continuação do racionamento nos municípios dependentes dos reservatórios afetados", terceira CT identificada. Essa causa é particularmente delicada, já que tais municípios foram "sacrificados" em benefício de um maior (Campina Grande), que, por sua vez, já saiu do racionamento desde o segundo semestre de 2017, enquanto a população das

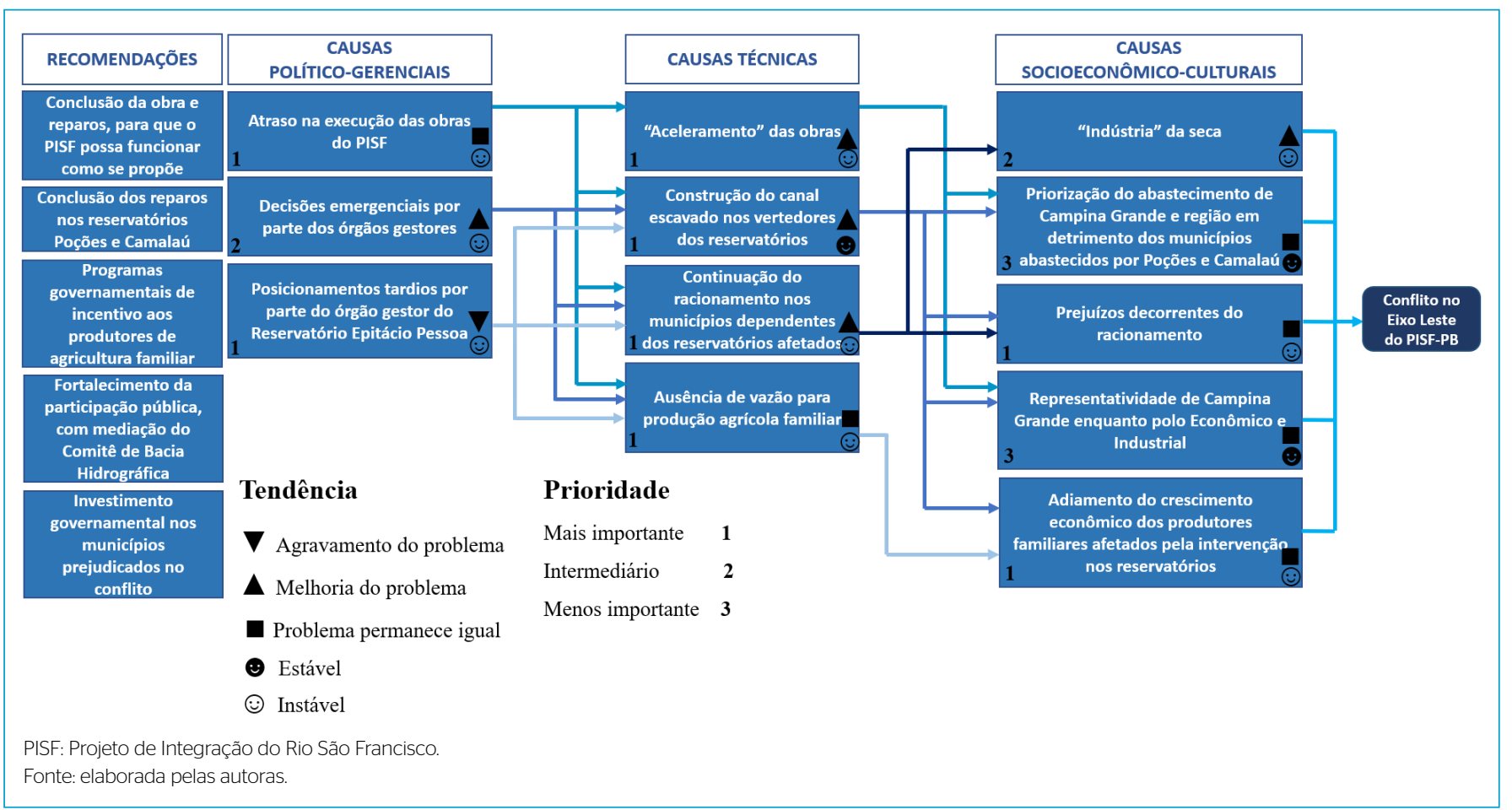

Figura 3 - Cadeia causal dos acontecimentos no Eixo Leste do Projeto de Integração do Rio São Francisco. 
cidades menores continuou a sofrer o prejuízo dessas intervenções por mais tempo. Como a causa anterior, essa causa apresenta uma tendência de melhoria, uma vez que as obras de reparo estão em andamento. Ela é considerada instável, já que o racionamento pode voltar a ocorrer caso o sistema apresente falhas. Essa causa tem ligação com as três CPG, e a ela foi atribuída prioridade 1 .

A quarta CT, "Ausência de vazão para produção agrícola familiar", assemelha-se à anterior pelo fato de ter conexão com todas as CPGs. Com a intervenção que impediu o armazenamento de água nos reservatórios e com as suspensões no bombeamento, não existe vazão para produção agrícola familiar. Essa causa apresenta uma tendência de permanência, considerando que mesmo com a conclusão dos reparos nas barragens e o funcionamento pleno do sistema, a priori, serão atendidas as demandas para abastecimento humano e dessedentação animal. Essa tendência, entretanto, é instável, pois espera-se que tal demanda seja atendida quando o sistema estiver com seu funcionamento regularizado. A essa causa foi atribuída prioridade 1.

\section{Causas socioeconômico-culturais}

Como primeira CSC é citada a "indústria da seca". Assim são chamados aqueles que se beneficiam dessa, que é uma consequência das características climáticas da região em união com a ausência de uma boa gestão de recursos hídricos. Donos de carros-pipa, vendedores de caixas d'água e principalmente políticos da região têm nesses períodos a "oportunidade" de lucrarem financeiramente ou com a angariação de votos, sob falsas promessas de soluções. Essa causa está ligada à CT "Continuação do racionamento nos municípios dependentes dos reservatórios afetados", uma vez que, em um ano relativamente chuvoso como 2018, a "indústria da seca" estaria adormecida não fossem as intervenções e os atrasos nas obras de correção das barragens afetadas. Essa causa apresenta uma tendência de melhoria com a proximidade do funcionamento pleno do PISF. Todavia, essa tendência é instável, pois pode ser alterada pela ocorrência de falhas no sistema e na gestão, atreladas à chegada de ciclos secos. Para essa causa foi atribuída prioridade 2 .

As CSCs "Priorização do abastecimento de Campina Grande e região em detrimento dos municípios abastecidos por Poções e Camalaú" e "Representatividade de Campina Grande enquanto polo Econômico e Industrial”, são ligadas às causas técnicas "Aceleramento das obras" e "Construção do canal escavado nos vertedores dos reservatórios". Estão diretamente conectadas ao peso econômico e produtivo do município de Campina Grande. Municípios pequenos (especialmente em termos econômicos) ficam desabastecidos para garantir o abastecimento de um município que é polo econômico, industrial, educacional e científico. Tais causas são consideradas permanentes, já que o município maior sempre será priorizado por razões culturais, logísticas e econômicas. Apenas com o fortalecimento institucional desses pequenos municípios, poderia haver reversão dessa situação. Assim, a tendência foi admitida como estável e foi atribuída prioridade 3 .

A CSC "Prejuízos decorrentes do racionamento" está diretamente ligada às CTs "Construção do canal escavado nos vertedores dos reservatórios" e "Continuação do racionamento nos municípios dependentes dos reservatórios afetados". Tais prejuízos são desde ordem econômica, uma vez que o racionamento afeta diretamente o comércio local, a prejuízos voltados para o desconforto pela falta de água, especialmente para a população periférica, em que a água demora mais a chegar e o armazenamento é muito precário. Tal causa apresenta uma tendência de permanência, visto que os prejuízos decorrentes da continuação do racionamento são muito reais. Contudo, essa tendência é instável, uma vez que, com o pleno funcionamento do PISF, o abastecimento da população será regularizado. Para essa causa foi atribuída prioridade 1.

Por fim, a CSC "Adiamento do crescimento econômico dos produtores familiares afetados pela intervenção nos reservatórios afetados" está ligada às CTs "Construção do canal escavado nos vertedores dos reservatórios" e "Ausência de vazão para produção agrícola familiar". Essa causa é um agravante considerável da problemática local. A população que depende da agricultura e que via na chegada das águas do São Francisco uma esperança de crescimento teve essa ideia frustrada pela situação de urgência, o que se mantém em decorrência dos atrasos nos reparos dos reservatórios. Com destaque para o caso da Vila Produtiva Rural Lafayette, um extremo das injustiças geradas pelo PISF. Essa causa apresenta uma tendência de permanência e instabilidade pelas razões já explicadas na CT "Ausência de vazão para produção agrícola familiar". Para essa causa foi atribuída prioridade 1 .

O Quadro 1 apresenta um resumo das causas, suas tendências e prioridades.

\section{Recomendações}

Com base na ACC, são apresentadas, a seguir, recomendações acerca do conflito de segunda ordem em questão.

Faz-se necessária a continuação da obra do PISF, visando à sua conclusão, bem como dos reparos para os casos nos quais a obra apresentou falhas. Quando concluído, o PISF poderá trazer segurança hídrica, como é seu objetivo, para a população do Nordeste Setentrional. Tal questão se relaciona com todas as causas da cadeia, uma vez que, estando o PISF em pleno funcionamento, esse conflito teria sido evitado.

A conclusão dos reparos nas barragens Poções e Camalaú é indispensável na resolução desse conflito. Tal fato se dá pela necessidade de permitir que os reservatórios desempenhem sua função social, garantindo a possibilidade de armazenamento de água e, por conseguinte, o abastecimento da população a ser atendida por esses. Tal recomendação está relacionada à CPG 2 , às CTs 2,3 e 4 , e às CSCs 1, 2, 3 e 5 (considerando a ordem na qual as causas aparecem na Figura 3).

Uma forma de mitigar os impactos na produção agrícola familiar das famílias atingidas pelo desabastecimento dos reservatórios Poções e Camalaú, bem como das famílias realocadas na Vila Produtiva Rural Lafayette, seria o apoio governamental para os pequenos produtores. Tal apoio poderia advir de programas de incentivo à agricultura familiar. Tal recomendação se relaciona com as CTs 2, 3 e 4, e com as CSCs 1, 3 e 5 (considerando a ordem na qual as causas aparecem na Figura 3).

Para atingir a raiz do problema, melhorar a governança hídrica na região, é indispensável o fortalecimento da participação pública na gestão das águas. Um caminho para esse fortalecimento está no Comitê de Bacia Hidrográfica do rio Paraíba. Uma boa governança necessita da participação de todos os envolvidos, e o comitê de bacia permite à população maior representatividade e participação nas decisões que envolvem os recursos hídricos. A Lei no 9.433/1997, no seu artigo 38, determina que "Compete aos Comitês de Bacia Hidrográfica [...] II - arbitrar, em primeira instância administrativa, os conflitos relacionados aos recursos hídricos" (BRASIL, 1997). Algo que não se verificou no caso estudado. O fortalecimento da participação pública se relaciona com as CPGs 2 e 3 (considerando a ordem na qual as causas aparecem na Figura 3). 
Por fim, os prejuízos causados pela ineficiência na governança hídrica e, mais especificamente, na execução das obras do PISF são uma realidade. Uma forma de reparar, minimamente, a população afetada seria o investimento governamental em obras que possibilitariam melhor qualidade de vida aos atingidos pelo conflito. Nesse sentido, investimentos em saneamento básico gerariam melhorias para a população e garantiriam a manutenção da qualidade das águas dos mananciais.

\section{CONCLUSÕES}

A ACC permitiu sistematizar o conflito de segunda ordem, ocasionado pela problemática da chegada das águas do rio São Francisco ao seu Eixo Leste, possibilitando a identificação de suas causas e os inter-relacionamentos entre elas. Dessa forma, CPGs (como o atraso na execução das obras do PISF), CTs (aceleramento das obras, ausência de vazão para a produção agrícola familiar), e CSCs (prioridade do abastecimento para centros urbanos maiores em detrimento dos menores) foram identificadas possibilitando melhor entender o conflito e indicar recomendações para o seu encerramento. A análise permitiu identificar, ainda, a tendência em termos de agravamento, melhoria ou permanência do problema assim como categorizar as causas em termos de mais, menos ou de intermediária importância. Dessa forma, é possível concluir que a ACC foi um método capaz de bem sistematizar a problemática, auxiliando a ressaltar aspectos relevantes do conflito de segunda ordem estudado.

Depreende-se da análise que, por ausência de adequada gestão hídrica, o REP atingiu 3\% do seu volume armazenado (em abril de 2017), o menor valor da sua história. Diante dessa situação, a tradicional solução hidráulica da expansão da oferta se tornou a única solução possível: a transposição das águas do rio São Francisco. O conflito pelo uso da água aqui analisado se caracterizou como um conflito de segunda ordem surgido em consequência de uma introdução inadequada de uma medida para resolver uma escassez, na sua origem, de primeira ordem. A medida inadequada se configura na forma acelerada como foi executado o Eixo Leste do PISF, gerando dificuldades para usuários situados a montante do REP, como aqueles da Vila Produtiva Rural Lafayette - população que necessita de proteção para superar o problema.
A crise hídrica incentivou ações conjuntas dos órgãos envolvidas (como as resoluções ANA e AESA), indicando uma tentativa de disciplinar o uso da água na região. Com a chegada das águas do PISF, os órgãos têm participado do acompanhamento das obras no Eixo Leste. As decisões em relação às regras de uso e alocação das águas do REP e do curso do rio Paraíba também têm sido discutidas com participação dos usuários e da sociedade civil.

Essa é uma consequência positiva da crise: incentivar melhor articulação entre as agências de água. Para o caso em questão, esse aspecto tem muita relevância em função da complexidade da gestão gerada pela dupla dominialidade: águas de domínio da União (REP) em uma bacia hidrográfica de rio de domínio estadual (a bacia do rio Paraíba). Complexidade acrescida com a chegada das águas do rio São Francisco (de domínio da União).

Outro aspecto importante é a elaboração dos planos de segurança de barragem como uma política preventiva e não remediadora. O cadastro dos irrigantes, usuários da água do Sistema rio Paraíba - REP, também é medida importante em direção à correção de um grave erro: a sempre permissão de uso da água por parte daqueles usuários.

Assim, em que pese os sérios conflitos gerados, a cadeia causal aplicada ao caso em estudo indica que há tendência de melhoria para alguns dos aspectos averiguados. Deve-se, entretanto, considerar algumas premissas para a melhoria da gestão nessa região: a segurança hídrica trazida pelo PISF não pode ser entendida como absoluta. É preciso usar, sempre, a água de forma responsável considerando as características peculiares de uma região semiárida e as condições hidrológicas da Bacia do rio São Francisco - agora, integrada à Bacia do rio Paraíba. Nesse sentido, as ações de gerenciamento da demanda urbana e rural serão sempre essenciais.

\section{CONTRIBUIÇõES DOS AUTORES}

Nunes, T. H. C.: Conceituação, Curadoria de Dados, Investigação, Metodologia, Validação, Escrita - Primeira Redação, Escrita - Revisão e Edição. Ribeiro, M. M. R.: Conceituação, Análise Formal, Obtenção de Financiamento, Investigação, Metodologia, Supervisão, Escrita - Primeira Redação, Escrita - Revisão e Edição.

\section{REFERÊNCIAS}

AGÊNCIA EXECUTIVA DE GESTÃO DAS ÁGUAS (AESA). Volume de Açudes - Açude: Epitácio Pessoa. Disponível em: http://www.aesa.pb.gov. br/aesa-website/monitoramento/volume-acude/?id_acude=531. Acesso em: 20 jul. 2020

AGÊNCIA NACIONAL DE ÁGUAS (ANA). Reservatórios do semiárido brasileiro: hidrologia, balanço hídrico e operação: Anexo A. Brasília: ANA, 2017. $103 \mathrm{p}$.

AGÊNCIA NACIONAL DE AGUAS (ANA); AGÊNCIA EXECUTIVA DE GESTÃO DAS AGUAS (AESA). Resolução Conjunta ANA e AESA no 87. Documento no 00000.065740/2018-29. 5 nov. 2018.

AGÊNCIA NACIONAL DE ÁGUAS (ANA); AGÊNCIA EXECUTIVA DE GESTÃO DAS ÁGUAS (AESA). Resolução Conjunta ANA e AESA no 1.292. Documento no 00000.044837/2017-17. 17 jul. 2017.
AMORIM, A.L.; RIBEIRO, M.M.R.; BRAGA, C.F.C. Conflitos em bacias hidrográficas compartilhadas: o caso da bacia do rio Piranhas-Açu/PB-RN. Revista Brasileira de Recursos Hídricos, v. 21, n. 1, p. 36-45, 2016. http://dx.doi. org/10.21168/rbrh.v21n1.p36-45

BARBOSA, J. Água da transposição volta a ser bombeada e população de Monteiro comemora. Jornal da Paraíba, 2018. Disponível em: https://www. jornaldaparaiba.com.br/vida_urbana/agua-da-transposicao-volta-ser-bombeadae-populacao-de-monteiro-comemora.html. Acesso em: 30 nov. 2018.

BELAUSTEGUIGOITIA, J.C. Causal Chain Analysis and Root Causes: The GIWA Approach. Ambio, v. 33, n. 1-2, p. 7-12, 2004

BLANC, G.F.C.; FERRONATO, E.C.P.; MIRANDA, T.L.G. Análise da cadeia causal na Bacia do rio Iguaçu. In: SIMPÓSIO BRASILEIRO DE RECURSOS HÍDRICOS, 22., 2017. Anais... Porto Alegre: ABRH, 2017. 
BRASIL. Lei Federal no 9.433, de 8 de janeiro de 1997. Institui a Política Nacional de Recursos Hídricos, cria o Sistema Nacional de Gerenciamento de Recursos Hídricos. Brasil, 1997. Disponível em: http://www.planalto.gov. br/ccivil_O3/leis/19433.htm. Acesso em: 25 maio 2021.

BRASIL. Logo do Projeto São Francisco, Água a quem tem sede. Municípios Beneficiados. Ministério da Integração Nacional. Disponível em: http://www. integracao.gov.br/pt/c/document_library/get_file?uuid=8444b696-cf7641ed-8b4b-84b66923448f\&groupld=66920. Acesso em: 26 fev. 2019a.

BRASIL. Paralisação da operação do Eixo Leste do PISF para finalização das obras de recuperação nos reservatórios Poções e Camalaú. Nota Técnica no 06/2018/CGAOH/DPE/SIH. Brasília: Ministério da Integração Nacional, 2018. 3 p.

BRASIL. Projeto de Integração do rio São Francisco. Ministério da Integração Nacional. Disponível em: https://www.gov.br/mdr/pt-br/assuntos/segurancahidrica/projeto-sao-francisco. Acesso em: 27 fev. 2019b.

BRASIL. Projeto de Integração do Rio São Francisco com Bacias Hidrográficas do Nordeste Setentrional. Relatório de Impacto Ambiental. Ministério da Integração Nacional, 2004.

COMITÊ DA BACIA HIDROGRÁFICA DO RIO SÃO FRANCISCO (CBHSF). Shapefile dos eixos do PISF. CBHSF. Disponível em: http://www. saofrancisco.cbh.gov.br/Shapes/SHAPE.sigeo.Transposicao.SF.zip. Acesso em: 11 set. 2018

COMPANHIA DE AGUA E ESGOTOS DA PARAÍBA (CAGEPA). Sistemas de Abastecimento. CAGEPA. Disponível em: http://www.cagepa.pb.gov.br/ sistemas-de-abastecimento/. Acesso em: 14 dez. 2018.

DEPARTAMENTO NACIONAL DE OBRAS CONTRA ASSECAS (DNOCS). Nota Oficial - Projeto de Integração do Rio São Francisco. DNOCS. Disponível em: https://www2.dnocs.gov.br/gab-cs/noticias/4539-nota-oficial-projetode-integracao-do-rio-sao-francisco. Acesso em: 20 nov. 2019a.

DEPARTAMENTO NACIONAL DE OBRAS CONTRA AS SECAS (DNOCS). Obras nas Barragens de Camalaú e Poções avançam e estarão concluídas em breves. DNOCS. Disponível em: https://www2.dnocs.gov.br/gab-cs/ noticias/4244-obras-na-barragem-de-camalau-e-pocoes-avancam-eestarao-concluidas-em-breve. Acesso em: 14 fev. 2019b.

FLEURY, L.C.; ALMEIDA, J. A construção da usina hidrelétrica de Belo Monte: conflito ambiental e o dilema do desenvolvimento. Ambiente \& Sociedade, v. 16, n. 4, p. 141-156, 2013. http://dx.doi.org/10.1590/S1414$753 \times 2013000400009$

FREITAS, C. Old Chico's new tricks: Neoliberalization and water sector reform in Brazil's São Francisco River Basin. Geoforum, v. 64, p. 292-303, 2015. https://doi.org/10.1016/j.geoforum.2015.05.012

G1-PB. Conclusão das obras complementares à transposição na Paraíba tem novo prazo. G1, 2018. Disponível em: https:/g1.globo.com/pb/paraiba/ noticia/2018/08/08/conclusao-das-obras-complementares-a-transposicaona-paraiba-tem-novo-prazo.ghtml. Acesso em: 11 set. 2018.

G1-PB. População de Monteiro (PB) ainda sofre com o racionamento de água. G1, 2017. Disponível em: https://g1.globo.com/pb/paraiba/noticia/ moradores-de-monteiro-la-cidade-da-pb-a-receber-transposicao-sofremsem-agua.ghtml/. Acesso em: 10 out. 2019.

GLOBAL INTERNATIONAL WATERS ASSESSMENT (GIWA). Methodology: Detailed Assessment Causal Chain Analysis Policy Option Analysis. GIWA UNEP/GEF, 2002. 70 p.
HE, B.; CHEN, T.; YANG, X. Root cause analysis in multivariate statistical process monitoring: Integrating reconstruction-based multivariate contribution analysis with fuzzy-signed directed graphs. Computers and Chemical Engineering, v. 64, p. 167-177, 2014. https://doi.org/10.1016/j. compchemeng.2014.02.014

INSTITUTO BRASILEIRO DE GEOGRAFIA E ESTATÍSTICA (IBGE). Censo Demográfico: Tabelas - Unidades da Federação - Paraíba. IBGE, 2010. Disponível em: ftp://ftp.ibge.gov.br/Censos/Censo_Demografico_2010/Sinopse/ Unidades_da_Federacao/sinsino_uf_Paraiba.zip. Acesso em: 27 jan. 2019.

INSTITUTO NACIONAL DO SEMIÁRIDO (INSA). Sistema de Gestão da Informação e do Conhecimento do Semiárido Brasileiro (SIGSAB). INSA. Disponível em: http://sigsab.insa.gov.br/acervoDigital. Acesso em: 11 set. 2018.

KAMPEN, D. The SSQ model of schizophrenic prodromal unfolding revised: An analysis of its causal chains based on the language of directed graphs. European Psychiatry, v. 29, n. 7, p. 437-448, 2014. https://doi.org/10.1016/j.eurpsy.2013.11.001

KNEALE, D.; THOMAS, J.; BANGPAN, M.; WADDINGTON, H.; GOUGH, D. Conceptualising causal pathways in systematic reviews of international development interventions through adopting a causal chain analysis approach. Journal of Development Effectiveness, v. 10, n. 4, p. 422-437, 2018. https://doi.org/10.1080/19439342.2018.1530278

LEE, H.A.; PARK, H. The mediation effect of individual eating behaviours on the relationship between socioeconomic status and dietary quality in children: the Korean National Health and Nutrition Examination Survey. European Journal of Nutrition, v. 56, n. 3, p. 1339-1346, 2017. https://dx.doi. org/10.1007\%2FsO0394-016-1184-2

LEMAY JR., E.P.; RYAN, J.E. Interpersonal regulation of relationship partners' security: A causal chain analysis. Motivation and Emotion, v. 24, p. 774-793, 2018. https://doi.org/10.1007/s11031-018-9700-8

LIANG, W.; YONGLI, C.; HONGQUAN, C.; DALER, D.; JINGMIN, Z:; JUAN, Y. Flood disaster in Taihu Basin, China: causal chain and policy option analyses. Environment Earth Science, v. 63, p. 1119-1124, 2011. https://doi. org/10.1007/s12665-010-0786-x

LIAO, P.; SHI, H.; SU, Y.; LUO, X. Development of Data-Driven Influence Model to Relate the Workplace Environment to Human Error. Journal of Construction Engineering and Management, v. 144, n. 3, 2018. https://doi. org/10.1061/(ASCE)C0.1943-7862.0001448

MIANABADI, H.; MOSTERT, E.; ZARGHAMI, M.; GIESEN, N. A new bankruptcy method for conflict resolution in water resources allocation. Journal of Environmental Management, v. 144, p. 152-159, 2014. https://doi.org/10.1016/j. jenvman.2014.05.018

MIAO, X:; TANG, Y:; WONG, C.W.Y; ZANG, H. The latent causal chain of industrial water pollution in China. Environmental Pollution, v. 196, p. 473477, 2015. https://doi.org/10.1016/j.envpol.2014.11.010

MINISTÉRIO PÚBLICO FEDERAL DA PARAÍBA (MPF-PB). Decisão. Processo no 0800199-46.2017.4.05.8203 - ação civil pública. Monteiro: Ministério Público Federal, Procuradoria da República na Paraíba, 2019a. 4 p.

MINISTÉRIO PÚBLICO FEDERAL DA PARAÍBA (MPF-PB). MPF bUSCa solucionar problema de 61 famílias em Monteiro (PB) prejudicadas com a transposição do São Francisco. Monteiro: Ministério Público Federal, Procuradoria da República na Paraíba, 2019b. Disponível em: http://www.mpf.mp.br/pb/sala-de-imprensa/noticias-pb/mpf-buscasolucionar-problema-de-61-familias-em-monteiro-pb-prejudicadas-com-atransposicao-do-sao-francisco. Acesso em: 16 out. 2019. 
MINISTÉRIO PÚBLICO FEDERAL DA PARAÍBA (MPF-PB). MPF e MPPB vistoriam tomadas de água de Poções e Camalaú. Monteiro: Ministério Público Federal, Procuradoria da República na Paraíba, 2018a. Disponível em: http:// www.mpf.mp.br/pb/sala-de-imprensa/noticias-pb/transposicao-mpf-e-mppbvistoriam-tomadas-de-agua-de-pocoes-e-camalau. Acesso em: 30 nov. 2018.

MINISTÉRIO PÚBLICO FEDERAL DA PARAÍBA (MPF-PB). MPF pede bloqueio de R\$1 milhão em contas de órgãos que não apresentaram planos de segurança de barragens na PB. Monteiro: Ministério Público Federal, Procuradoria da República na Paraíba, 2019c. Disponível em: http://www.mpf.mp.br/pb/sala-de-imprensa/ noticias-pb/mpf-pede-bloqueio-de-r-1-milhao-de-contas-de-orgaos-que-naoapresentaram-planos-de-seguranca-de-barragens-na-pb-1. Acesso em: 15 fev. 2019.

MINISTÉRIO PÚBLICO FEDERAL DA PARAÍBA (MPF-PB). Recomendação no 5/2019. Monteiro: Ministério Público Federal, Procuradoria da República na Paraíba, 2019d. 4 p.

MINISTÉRIO PÚBLICO FEDERAL DA PARAÍBA (MPF-PB). Resposta à solicitação da Procuradoria Federal. Informação Técnica MPF/PRPB n.o 04/2019. Monteiro: Ministério Público Federal, Procuradoria da República na Paraíba, 2019e. 4 p.

MINISTÉRIO PÚBLICO FEDERAL DA PARAÍBA (MPF-PB). Vistoria técnica nas obras de modernização readequação dos açudes de Poções e Camalaú. Informação Técnica MPF/PRPB n.o 11/2018. Monteiro: Ministério Público Federal, Procuradoria da República na Paraíba, 2018b. 7 p.

NETHERLANDS ORGANIZATION FOR SCIENTIFIC RESEARCH (NOSR). Conflict and Security - final version. Hague: NOSR, 2007.

ORGANIZAÇÃO PARA A COOPERAÇÃO E DESENVOLVIMENTO ECONÔMICO (OECD). Water Governance in OECD Countries: A Multi-level Approach, OECD Studies on Water. Paris: OECD, 2011.

OHLSSON, L. Environment, Scarcity and Conflict - A study of Malthusian concerns. Tese (Doutorado) - Department of Peace and Development Research, University of Göterborg, 1999

OHLSSON, L. Water conflict and social resource scarcity. Physics and Chemistry of the Earth, part B: Hydrology, Oceans and Atmosphere, v. 25, n. 3, p. 213-220, 2000. https://doi.org/10.1016/S1464-1909(00)00006-X

OHLSSON, L.; TURTON, A.R. The turning of a screw. Social resource scarcity as a bottle-neck in adaptation to water scarcity. Londres: School of Oriental and African Studies Water Study Group, University of London, 1999.

OLIVEIRA, C.M.; ZANQUIM JUNIOR, J.W.; ESPINNDOLA, I.B. O Tribunal Arbitral como Instrumento Jurídico Alternativo de Solução de Conflitos Hídricos no Brasil. Ambiente \& Sociedade, v. 19, n. 1, p. 147-164, 2016. http://dx.doi. org/10.1590/1809-4422asoc150150r1v1912016

PAHL-WOSTL, C. An evolutionary perspective on water governance: From understanding to transformation. Water Resources Management, v. 31, p. 2917-2932, 2017. https://doi.org/10.1007/s11269-017-1727-1

PRESSE, A. Is water really a scarce resource? Initating entrepreneurship for global clean water supply. In: HIPEL, K.; FANG, L.; CULLMANNA, J.; BRISTOW, M. (org.). Conflict Resolution in Water Resources and Environmental Management. Nova York: Springer, 2015. p. 111-131.

RÊGO, J.C:; GALVÃO, C.O; ALBUQUERQUE, J.P.T. Considerações sobre a gestão dos recursos hídricos do açude Epitácio Pessoa - Boqueirão na bacia hidrográfica do Rio Paraiba em cenário de vindouros anos secos. In: SIMPÓSIO DE RECURSOS HIDRICOS DO NORDESTE, 11, 2012. Anais [...]. João Pessoa: ABRH, 2012.
RÊGO, J.C:; GALVÃO, C.O; ALBUQUERQUE, J.P.T.; RIBEIRO, M.M.R.; NUNES, T.H.C. A Gestão de Recursos Hídricos e a Transposição de Águas do Rio São Francisco para o açude Epitácio Pessoa - Boqueirão. In: SIMPÓSIO BRASILEIRO DE RECURSOS HÍDRICOS, 22., 2017. Anais... Florianópolis: ABRH, 2017.

RÊGO, J.C.; GALVÃO, C.O.; RIBEIRO, M.M.R.; ALBUQUERQUE, J.P.T.; NUNES, T.H.C. Novas considerações sobre a gestão dos recursos hídricos do Açude Epitácio Pessoa - A seca 2012-2014. In: SIMPÓSIO DE RECURSOS HÍDRICOS DO NORDESTE, 12., 2014. Anais... Natal: ABRH, 2014.

RÊGO, J.C.; GALVÃO, C.O.; VIEIRA, Z.M.C.L.; RIBEIRO, M.M.R.; ALBUQUERQUE, J.P.T.; SOUZA, J.A. Atribuições e responsabilidades na gestão dos recursos hidricos - o caso do açude Epitácio Pessoa/Boqueirão no Cariri paraibano. In: SIMPÓSIO BRASILEIRO DE RECURSOS HÍDRICOS, 20., 2013. Anais [...]. Bento Gonçalves: ABRH, 2013.

RIBEIRO, M.M.R.; AMORIM, A.L.; FERREIRA, J.G.; SCHMIDT, L. Bacias hidrográficas compartilhadas no Brasil e na Península Ibérica: buscando consensos via mecanismos de resolução de conflitos. In: PHILIPPI JR., A.; SOBRAL, M. C. (org.). Gestão de Bacias Hidrográficas e Sustentabilidade. Barueri: Manole, 2019. p. 1020-1046.

RODORFF, V.; SIEGMUND-SHULTZE, M.; KÖPPEL, J.; GOMES, E.T.A. Governança da Bacia Hidrográfica do Rio São Francisco: Desafios de Escala Sob Olhares Inter e Transdisciplinares. Revista Brasileira de Ciências Ambientais, n. 36, p. 19-44, 2015. https://doi.org/10.5327/Z2176-947820151003

SAVENIJE, H.H.G.; VAN DER ZAAG, P. Water as an economic good and demand management: paradigms and pitfalls. Water International, v. 27, n. 1 , p. 98-104, 2002. https://doi.org/10.1080/02508060208686982

SCHRAM, A.; RUCKERT, A.; VANDUZER, J.A.; FRIEL, S.; GLEESON, D.; THOW, A.; STUCKLER, D.; LABONTE, R. A conceptual framework for investigating the impacts of international trade and investment agreements on noncommunicable disease risk factors. Health Policy and Planning, v. 33, n. 1. p. 123-136, 2018. https://doi.org/10.1093/heapol/czx133

SCHULZ, C.; MARTIN-ORTEGA, J.; GLENK, K.; IORIS, A.A.R. The Value Base of Water Governance: A Multi-Disciplinary Perspective. Ecological Economics, v. 131, p. 241-249, 2017. https://doi.org/10.1016/j.ecolecon.2016.09.009

SILVA, J.M.; GURGEL, I.G.D.; SANTOS, M.O;:GURGEL, A.M:; AUGUSTO, L.G.S.; COSTA, A.M. Conflitos ambientais e as águas do rio São Francisco. Saúde e Sociedade, v. 24, n. 4, p. 1208-1216, 2015. http://dx.doi.org/101590/SO104-12902015137316

SILVA, P.H.P.; RIBEIRO, M.M.R; MIRANDA, L.I.B. Uso de cadeia causal na análise institucional da gestão de recursos hídricos em reservatório no semiárido da Paraíba. Engenharia Sanitária e Ambiental, v. 22, n. 4, p. 637 646, 2017. http://dx.doi.org/10.1590/s1413-41522017149982

SOARES, G.C.S. Cadeia causal da degradação de nascentes na bacia hidrográfica do rio Gramame - Paraíba. 123f. Dissertação (Mestrado) Programa de Pós-Graduação em Engenharia Civil e Ambiental, Universidade Federal da Paraíba, João Pessoa, 2015.

WHITE, H. Theory-based systematic reviews. Journal of Development Effectiveness, v. 10, n. 1, p. 17-38, 2018. https://doi.org/10.1080/19439342.2 018.1439078

ZOU,Y.; DUAN, X:; XUE,Z.; E, M.;SUN, M.:LU, X.; JIANG, M.; YU,X. Water use conflict between wetland and agriculture. Journal of Environmental Management, v. 224, p. 140-146, 2018. https://doi.org/10.1016/j.jenvman.2018.07.052

(c) 2021 Associação Brasileira de Engenharia Sanitária e Ambiental Este é um artigo de acesso aberto distribuído nos termos de licença Creative Commons. 